\title{
Regional Variability in the Use of CT for Patients with Suspected Mild Traumatic Brain Injury
}

\author{
Won Hyung A. Ryu, Anthony Feinstein, Angela Colantonio, David L. Streiner, \\ Deirdre Dawson
}

\begin{abstract}
Objective: To investigate the use of computed tomography (CT) scans in patients with suspected acute mild traumatic brain injury (mTBI) presenting to emergency departments. Method: 850 potential mTBI cases were identified through reviews of three months of health records from nine selected emergency departments across the province of Ontario. Records for review were selected using the International Classification of Disease, 9th revision, Clinical Modification codes and Injury codes. Results: Patients who received head CT were significantly older ( $<<0.01)$, had documented loss-of-consciousness (LOC) \&/or Post-Traumatic Amnesia (PTA) $(\mathrm{p}<0.001)$, documented nausea $(\mathrm{p}<0.01)$, documented vomiting $(\mathrm{p}<0.001)$, abnormal neurological exam results $(\mathrm{p}<0.01)$, had visited an urban center $(\mathrm{p}<0.001)$, and/or arrived by ambulance $(\mathrm{p}<0.001)$. The significant predictors of CT scan prescription (in a forward stepwise logistic regression) were urban location of hospital (OR=5.14; $\mathrm{p} \leq 0.001)$, LOC \&/or PTA $(\mathrm{OR}=4.83$; $\mathrm{p} \leq 0.001)$, vomiting $(\mathrm{OR}=2.56 ; \mathrm{p} \leq 0.01)$, arrival by ambulance $(\mathrm{OR}=2.15 ; \mathrm{p} \leq 0.001)$, nausea $(\mathrm{OR}=1.92 ; \mathrm{p}=\leq 0.02)$ and older age $(\mathrm{OR}=1.02 ; \mathrm{p} \leq 0.01)$. Conclusion: These data extend our knowledge regarding the use of CT during acute diagnosis and management of suspected mTBI patients. In addition to confirming previously reported risk factors of intracranial complication, geographical location of hospital and arrival mode were found to be significant predictors of CT use. The results suggest that the management patterns for acute mTBI are inconsistent. The implications of this are discussed.
\end{abstract}

RÉSUMÉ: Variabilité régionale dans l'utilisation de la TDM chez les patients chez qui on soupçonne une lésion cérébrale traumatique légère. Objectif : Le but de cette étude était d'examiner l'utilisation de la tomodensitométrie (TDM) chez les patients qui se présentent à la salle d'urgence et chez qui on soupçonne la présence d'une lésion cérébrale traumatique légère ( $\mathrm{LCTl}$ ). Méthode : Huit cent cinquante cas de LCTl potentielle ont été identifiés par une revue des dossiers médicaux sur une période de trois mois dans 9 salles d'urgence choisies à travers l'Ontario. Les dossiers ont été choisis à l'aide de la International Classification of Disease, 9th revision, Clinical Modification Codes and Injury Codes. Résultats : Les patients qui ont subi une TDM cérébrale étaient significativement plus âgés $(\mathrm{p}<0,01)$, avaient subi une perte de conscience (PDC) authentifiée et/ou une amnésie post-traumatique (APT) $(\mathrm{p}<0,001)$, un état nauséeux authentifié $(\mathrm{p}<0,01)$, des vomissements authentifiés $(\mathrm{p}<0,01)$, un examen neurologique anormal $(\mathrm{p}<0,001)$, avaient consulté dans un centre urbain $(\mathrm{p}<0,001)$ et/ou étaient arrivés par transport ambulancier $(\mathrm{p}<0,001)$. Les éléments prédicteurs significatifs d'une prescription de TDM (à l'analyse de régression logistique pas à pas antérograde) étaient l'hôpital situé dans une ville (RC = 5,14; $\mathrm{p}$ $\leq 0,001)$, la PDC et/ou l'APT ( $\mathrm{RC}=4,83 ; \mathrm{p} \leq 0,001)$, les vomissements $(\mathrm{RC}=2,56 ; \mathrm{p} \leq 0,001)$, l'arrivée par transport ambulancier $(\mathrm{RC}=2,15 ; \mathrm{p} \leq$ $0,001)$, l'état nauséeux $(R C=1,92 ; p \leq 0,002)$ et l'âge plus avancé $(R C=1,02 ; p \leq 0,001)$. Conclusion : Ces données ajoutent à nos connaissances de l'utilisation de la TDM en phase aiguë du diagnostic et du traitement de patients chez qui on soupçonne une LCTl. En plus de confirmer les facteurs de risque de complications intracrâniennes rapportés antérieurement, nous avons constaté que le lieu géographique de l'hôpital et le mode de transport étaient des prédicteurs significatifs de l'utilisation de la TDM. Ces résultats nous portent à croire que la façon de prendre en charge une LCTl varie beaucoup et nous discutons des implications de nos constatations.

Can. J. Neurol. Sci. 2009; 36: 42-46

Computed tomography (CT) has become the most common means for detecting early intracranial abnormalities after traumatic brain injury (TBI). ${ }^{1}$ However, there has been considerable uncertainty regarding whether everyone who receives a CT scan in the potential mild TBI (mTBI) population in fact needs one. With approximately $90 \%$ of brain imaging being negative after mTBI, patients without intracranial
From the Kunin-Lunenfeld Applied Research Unit (WHAR, DLS, DD), Baycrest; Department of Occupational Science \& Occupational Therapy (AC, DD), Graduate Department of Rehabilitation Science (WHAR, AC, DD), Department of Psychiatry (AF, DLS), University of Toronto; Sunnybrook Health Sciences Centre (AF,); Toronto Rehabilitation Institute (WHAR, AC, DD), Toronto, Ontario, Canada.

Received January 28, 2008. Final Revisions Submitted July 10, 2008. Correspondence to: Deirdre Dawson, Kunin-Lunenfeld Applied Research Unit, Baycrest, 3560 Bathurst St., Toronto, Ontario, M6A 2E1, Canada. 
complications are being unnecessarily exposed to $\mathrm{x}$-ray radiation. ${ }^{1,2}$ Ideally, the risk factors for complications should dictate the need for brain imaging - ensuring a consistent quality of medical care across different primary care settings. This is particularly important in Canada where equitable access to health care forms part of the Canadian Health Act. However, the heterogeneity found both between and within hospitals suggests that there are other factors influencing the use of CT for mTBI cases. ${ }^{3}$ Anecdotal evidence and previously published reports of regional variability in other medical services such as hospital admission, surgery and diagnostic procedures suggest that examining the influence of geographic location of the hospitals may shed light on the use of CT scans ${ }^{4-6}$ Furthermore, given that approximately $32 \%$ of Canadians live in non-urban areas which make up 99\% of Canada's land area, heterogeneity in acute diagnosis and management of mTBI at different types of care settings, specifically urban versus rural centres, is an important issue. $^{7}$

This study investigates the determinants of CT use during the acute diagnosis and management of mTBI. The specific objectives are: (1) to compare patients with suspected mTBI who received CT and those who did not; (2) to identify variables that are significantly associated with the use of CT scans during the acute diagnosis of mTBI patients; (3) to determine the odds of receiving a CT scan based on the variables found to be significantly associated with CT use. Our hypothesis is that in addition to previously reported clinical predictors, geographical location of the emergency department (ED) will predict the use of CT for patients with suspected mTBI.

\section{METHODS}

\section{Design}

This study used a retrospective cross-sectional design.

\section{Sample}

Three months of health records were retrospectively reviewed from nine ED representing the five different geographical regions in Ontario designated by the Ontario Hospital Association. ${ }^{8}$ The hospitals were selected to ensure that the following were represented: urban trauma centres, urban nontrauma centres, university affiliated centres and rural centres. Urban centres are EDs located in metropolitan areas defined as areas with a population of at least $100,000 .^{7}$ All EDs in smaller metropolitan areas were classified as rural. In this study, there were four urban centres and five rural centres. Each of the nine participating centres had on-site CT scanners. Each centre provided ethics approval for this study as did the Baycrest Research Ethics Board. Records for review were selected using the International Classification of Disease, 9th revision, Clinical Modification codes for head injury (ICD-9-CM 800-804; 850854) and E-codes for any injuries involving acceleration/ deceleration (complete list of codes available from the author). Patients were deemed potential mTBI cases if they had received a diagnosis of concussion, or mild brain injury in the ED. For the patients who did not receive the above diagnosis, they were included if they showed at least one of the criteria from the American Congress of Rehabilitation Medicine (ACRM) definition of mTBI; 1) any loss of consciousness (LOC), 2) any loss of memory for events immediately before or after the injury, 3) any alteration in mental state at the time of the injury (e.g. disoriented, or confused), and 4) focal neurological deficit(s) that may or may not be transient. ${ }^{9}$ Patients were excluded if they had; 1) LOC of greater than 30 minutes, 2) Post-traumatic amnesia (PTA) greater than 24 hours, and/or 3) Glascow Coma Scale (GCS) scores of less than 13.9 Also, patients under 16 years-ofage were excluded. The ACRM definition was used in addition to the ED diagnosis to help ensure that cases were not missed.

\section{Procedure}

Two trained research assistants visited each participating site to review the health records and extract relevant patient information. Patient characteristics documented included: demographic data (age, gender), injury related data (mechanism of injury, presence and length of LOC or/and PTA, GCS, alcohol \&/or drug intoxication), examination data (headache, nausea, vomiting, head \& neck examination results, neurological examination results) and acute management data (head injury routine). The patient characteristics included were based on current research literature on risks factors of intracranial complications after mTBI and on factors important in the identification of mTBI. ${ }^{9-11}$ Other information included in the data collection were mode of arrival at the ED (ambulance or other) and the geographical location of the ED (urban or rural centres).

\section{Data Analysis}

Descriptive statistics were carried out to characterize the sample and to compare patients who received CT and those who did not. To determine if there were significant differences between the two groups (those who received CT and those who did not), Pearson chi-squared tests for nominal data and MannWhitney U test tests for continuous data were used. ${ }^{12}$ Following these analyses, phi coefficients between the independent variables were calculated to determine multicollinearity - with correlation of 0.9 suggesting multicollinearity. ${ }^{12}$ All correlations of independent variables in the study were below 0.5 . Thus, all significant independent variables from the univariate analyses were included in the regression analysis except for GCS scores. The GCS scores were not included in the logistic analysis due to the large amount of missing data which would have lowered the sample size of the logistic regression model to 313 from 850 patients. Logistic regression with forward stepwise selection analysis was used to identify the significant factors associated with the use of structural neuroimaging. Mechanism of injury was not included in the comparative or the regression analyses because the magnitude of acceleration/deceleration associated with the injury was not included in the patient charts. All analyses were conducted using Statistical Package for the Social Sciences 15.0 Software (SPSS 15.0) for Windows with significance of $\mathrm{p}<0.05$. No correction for multiple comparison were done in order to side towards inclusion of possible determinant variables given that regional variability in CT use has not been previously looked at. 


\section{Results}

Participating hospitals provided approximately 20,000 patient records based on the ICD codes and E-codes used and of these, 850 patients were identified as potential mTBI cases. Differences between patients who received head CT and those who did not are reported in Table 1 .

Patients who received CT scans were significantly older than patients who did not receive CT scans $(\mathrm{p}<0.01)$. The two groups significantly differed based on injury related data (presence of LOC or/and PTA, GCS), examination data (nausea, vomiting, neurological examination result), arrival mode and geographic location of the hospitals. The two groups did not differ on presence of headache, confusion and alcohol/drug intoxication. The major causes of mTBI were falls $(39 \%)$, motor vehicle crash $(22 \%)$ and assaults $(14 \%)$. The 106 of $850(12 \%)$ potential mTBI cases had documented alcohol or drug intoxication. Among the possible mTBI patients, $27 \%$ arrived at the primary care setting via ambulance. Of the 168 patients who received a CT scan, 55 patients did not receive a mTBI diagnosis. likely to receive CT scans. Given that some data, such as presence of LOC and/or PTA and mode of transport, were missing from some patient records, the sample size of the logistic regression model was reduced from 850 to 708 .

\section{DISCUSSION}

This study is the first to investigate regional variability in the use of CT scans after brain injury and more specifically in mTBI. We found that in addition to previously identified predictors, geographical location and arrival mode to the ED independently predicted whether or not people received CT scans. Specifically, patients presenting at an urban centre were five times more likely to receive brain imaging than those visiting rural EDs. Also, patients arriving by ambulance were two times more likely to receive CT scans than those who did not. While there are a number of interpretations for these findings, the most serious possible interpretation is that patients with mTBI and intracranial complications are more likely to be missed if they present at rural settings and if they do not arrive at the ED in an ambulance.

Table 1: Potential determinants of use of CT in suspected mTBI cases $(n=850)) \dagger$

\begin{tabular}{|c|c|c|c|c|}
\hline \multirow[b]{2}{*}{ Patient Characteristics } & \multirow[b]{2}{*}{ Overall } & \multicolumn{3}{|c|}{ Brain Radiography } \\
\hline & & $\begin{array}{l}\text { CT } \\
(\mathrm{n}=168)\end{array}$ & $\begin{array}{l}\text { No CT } \$ \\
(n=682)\end{array}$ & Effect Size \\
\hline - Dx of mTBI & $495 / 850$ & 113 & $382 *$ & 0.09 \\
\hline - $\quad$ LOC \&/or PTA & $228 / 711$ & 89 & $139 * *$ & 0.34 \\
\hline - $\quad$ GCS of 13-14 & $63 / 313$ & 37 & $26^{* *}$ & 0.24 \\
\hline - Headache & $380 / 850$ & 84 & 296 & 0.05 \\
\hline - Nausea & $149 / 850$ & 43 & $106^{*}$ & 0.11 \\
\hline - Vomiting & $53 / 850$ & 25 & $28 * *$ & 0.18 \\
\hline - Confusion & $64 / 82$ & 28 & 36 & 0.14 \\
\hline - $\quad$ Abnormal Head \& Neck Exam & $511 / 737$ & 92 & 419 & 0.03 \\
\hline - Abnormal Neurological Exam & $48 / 676$ & 25 & $23^{*}$ & 0.21 \\
\hline - Abnormal CT results & $31 / 850$ & 31 & N/A & \\
\hline - Drug/Alcohol Intoxication & $106 / 850$ & 22 & 84 & 0.01 \\
\hline - Arrival by Ambulance & $231 / 759$ & 83 & $148 * *$ & 0.25 \\
\hline - Visited Urban Centres & $592 / 850$ & 152 & $440 * *$ & 0.34 \\
\hline
\end{tabular}

$\dagger \mathrm{n}$ value for some variables are less than 850 due to missing data; $\$$ Asterisks show significant differences between CT and No CT groups determined by Chi-square test; $* \mathrm{p}<0.01 * * \mathrm{p}<0.001 ; \mathrm{DX}=$ diagnosis

To determine the predictors of use of CT scans, the significant variables from the univariate analyses were included in a logistic regression analysis. The overall percentage of correctly predicted outcome by the logistic model was $82.4 \%$ (Table 2). Patients with suspected mTBI visiting an urban hospital were five times more likely to receive CT scans. Patients with documented LOC \&/or PTA were over four times more likely to receive CT scans. Lastly, patients who arrived by ambulance were almost twice as
Moreover, while it is possible that all patients in the rural EDs were managed appropriately, our results highlight a significant variability in the use of CT scans in the primary care settings across Ontario.

Regional variability in access to health care services are known to exist. ${ }^{4-6}$ For example, a study by the Canadian Medical Association noted marked regional differences in health care patterns in Ontario for asthma and congestive heart failure. ${ }^{4}$ The 
Table 2: Determinants of use of $\mathrm{CT}$ in suspected mTBI cases $(\mathrm{n}=708)$

\begin{tabular}{llll}
\hline Variables & Odds Ratio & $\mathbf{9 5 \%}$ CI & Significance \\
\hline Urban Center & 5.14 & $2.67-9.88$ & $\leq 0.001$ \\
LOC \&/or PTA & 4.83 & $3.13-7.46$ & $\leq 0.001$ \\
Vomiting & 2.56 & $1.25-5.40$ & $\leq 0.01$ \\
Arrival by Ambulance & 2.15 & $1.37-3.38$ & $\leq 0.001$ \\
Nausea & 1.92 & $1.12-3.28$ & $\leq 0.02$ \\
Age & 1.02 & $1.01-1.02$ & $\leq 0.01$ \\
\hline
\end{tabular}

proposed explanations for this regional variability include difference in health care resources, variability in physician practice, and lack of agreement on optimal management. ${ }^{4,5,13}$

With regards to the current study findings, the regional variability in the use of CT for mTBI may reflect a difference in available health resources between the urban and rural centres. While all participating EDs had on-site CT scanners, urban centres may provide greater access to brain radiography with multiple CT scanners and more available scan time. Additionally, given that the availability of radiologists and $\mathrm{CT}$ technicians in rural EDs tend to be lower than in urban centres, the attending physicians may be inclined towards using in-hospital observation (e.g. being awakened every two hours to look for any changes in symptoms). This hypothesis was supported by our post-hoc analysis which showed that the use of head-injury routine was higher than expected in rural centres. Examining the time of day that patients visited the ED in future studies may further clarify the influence of available health resources (e.g. availability of radiologist, technician) on the variability of CT use. Another possible factor contributing to the regional variability is the issue of ED wait time. Specifically, patients with minimal symptoms in busy urban EDs may be scanned in order to be discharged quicker and thus freeing up the beds for more serious cases. Differences in physician knowledge may also contribute to regional variability in the use of CT scans. Related to the issue of discrepancy in physician knowledge, regional variability may also be influenced by whether the centre was university affiliated teaching hospital or not. In this study, all rural centres were non-teaching hospitals and half of the urban centres were teaching hospitals, the difference in the use of CT scans in urban centres may reflect teaching hospitals' inclination towards ordering head CTs for educational purposes.

The patients' arrival mode was also found to influence the use of CT in mTBI cases, with patients arriving by ambulance having twice the odds of receiving brain imaging than those who did not. The influence of arrival mode in CT scan use may be due to the physicians' assumption that patients requiring ambulance have greater trauma than those who managed to arrive at the ED by their own means. Another factor may be that ambulance personale may be better in observing and conveying the patient's injury related information to the physicians than family members or friends brining a patient to the hospital. The other factors we found to be significant in predicting CT use were age, LOC \&/or PTA, nausea, and vomiting. These patient characteristics are consistent with the literature on risk factors of intracranial complications. ${ }^{14-16}$

Two variables excluded from the regression model that require further consideration are the neurological examination results and the GCS scores. The contribution of acute neurological examination results in the physicians' decision to use CT scan is supported by the univariate analysis which shows that individuals with focal neurological symptoms received more head CTs than those without abnormalities. However, in our dataset 174 records did not indicate whether or not a neurological examination had been done. Rather than assume that the lack of a report of an exam meant that findings were normal, we elected to exclude this variable from our regression analyses. Based on the same reasoning, the GCS scores were excluded from the regression analysis given that 537 of 850 records did not have GCS scores. The exclusion of GCS from the regression model may be seen as problematic since it is commonly used for determining severity of brain injury. However, GCS scores have limited utility in diagnosing mTBI for several reasons. Firstly, the developers, Teasdale and Jennett, did not originally intend the GCS to distinguish milder types of injury. This is reflected by the fact that while there are 10 scale points ( 3 to 12 ) for severe and moderate cases that represent $20 \%$ of TBI cases, only two scale points are available to accommodate the remaining $80 \%$ of mTBI cases (13 and 14). ${ }^{17}$ Also, given that a significant number of individuals with mTBI achieve a perfect score of 15, the GCS provides no help in determining whether mild brain injury has occurred. ${ }^{18}$

A limitation in the interpretation and the generalizability of this study is the representativeness of these data. Our funding allowed us to collect data from only nine EDs of 170 in Ontario that have on-site CT scanners. However, these centres were specifically selected from each of five different geographic regions within Ontario as designated by the Ontario Hospital Association, and to include urban and rural centres. The data analyses did not compare trauma versus non-trauma centres or teaching versus non-teaching centres because all trauma and university affiliated centres were in urban areas with a large overlap between the trauma and university affiliated centres. We suspect similar variability in diagnostic practices would occur at other sites across the province. Another limitation of this study stems from the use of ICD-9 codes for case detection since some mTBI cases in the hospital records may have been missed if they were coded as something other than our selection criteria. For example, previous research has shown ICD-9 code 850 (concussion), the most frequently used diagnostic code for detecting mTBI cases, to include patients who did not have mTBI. ${ }^{19}$ In effort to ensure more inclusive case ascertainment, we included all injuries that involve sudden acceleration/ deceleration using the E-codes.

Despite these limitations, it is clear that there is tremendous variability in the use of $\mathrm{CT}$ in potential mTBI cases. Future studies examining the knowledge of physicians concerning the acute diagnosis of mTBI are warranted and could provide direction for continuing education courses for physicians. The findings in this study suggest that there are people with mTBI 
who are not being diagnosed in the ED. A more in-depth look at these 'missed' cases is warranted. By quantifying and describing these 'missed' mTBI cases, the diagnosis pattern of primary care physicians concerning individuals with suspected mTBI can be better understood. Furthermore, by applying published imaging guidelines to these 'missed' cases, concerns of inappropriate under-scanning and/or over-scanning may be addressed., , $20^{1,20}$ Lastly, incorporating time of ED visit and hospital admission rates may help in interpreting the management practices of EDs for potential mTBI cases.

In conclusion, this study highlighted that along with previously reported risk indicators, geographical location of hospitals and patients' arrival mode influence the diagnostic practices of ED physicians in potential mTBI cases. The results provide further support for the use of brain imaging guidelines in order to establish consistency in the acute care system regarding early detection of mTBI. More importantly, management issues such as availability of CT scan time and technician operating the CT scan need to be addressed before these guidelines can be put into practice.

\section{ACKNOWLEDGEMENTS}

This research was made possible by a grant from the Ontario Neurotrauma Foundation to Dr. D. Dawson and Dr. A. Feinstein. Won Hyung A. Ryu was supported by fellowships from Canadian Institutes of Health Research (CIHR), Ontario Ministry of Training, Colleges and Universities (OGS), Baycrest, Toronto Rehabilitation Institute, and University of Toronto. The authors also gratefully acknowledge the support of the participating hospitals, and our research assistants: A. Hatvani, K. Kit, T. Koscik, K. Krpan, S. Mack, K. Menezes, M. Peer, and M. Ryan, and thank Dr. P. Verhoeff and Dr. J. Ween for reviewing earlier versions of this manuscript.

\section{REFERENCES}

1. Stiell IG, Wells GA, Vandemheen K, Clement C, Lesiuk H, Laupacis A, et al. The Canadian CT head rule for patients with minor head injury. Lancet. 2001 May 5;357(9266):1391-6.

2. Haydel MJ, Preston CA, Mills TJ, Luber S, Blaudeau E, DeBlieux $\mathrm{PM}$. Indications for computed tomography in patients with minor head injury. N Engl J Med. 2000 Jul 13;343(2):100-5.

3. Stiell IG, Wells GA, Vandemheen K, Laupacis A, Brison R, Eisenhauer MA, et al. Variation in ED use of computed tomography for patients with minor head injury. Ann Emerg Med. 1997 Jul;30(1):14-22.

4. Patterns of Health Care in Ontario. 2nd ed. Goel V, Canadian Medical Association, Institute for Clinical Evaluative Sciences in Ontario, editors. Ottawa: Published by the Canadian Medical Association [for] the Institute for Clinical Evaluative Sciences in Ontario; 1996.
5. Small-area variations: What are they and what do they mean? Health services research group. CMAJ. 1992 Feb 15;146(4):46770.

6. Iscoe NA, Goel V, Wu K, Fehringer G, Holowaty EJ, Naylor CD. Variation in breast cancer surgery in Ontario. CMAJ. $1994 \mathrm{Feb}$ $1 ; 150(3): 345-52$.

7. 2006 census [homepage on the Internet]. Available from: http://www12.statcan.ca/.

8. Ontario Hospital Association regions [homepage on the Internet]. Available from: http://www.oha.com/.

9. Mild Traumatic Brain Injury Committee of the Head Injury Interdisciplinary Special Interest Group of the American Congress of Rehabilitation Medicine. Definition of mild traumatic brain injury. J Head Trauma Rehabil. 1993 September; 8(3):86-7.

10. Vos PE, Battistin L, Birbamer G, Gerstenbrand F, Potapov A, Prevec T, et al. EFNS guideline on mild traumatic brain injury: report of an EFNS task force. Eur J Neurol. 2002 May;9(3): 207-19.

11. Borg J, Holm L, Cassidy JD, Peloso PM, Carroll LJ, von Holst H, et al. Diagnostic procedures in mild traumatic brain injury: results of the WHO collaborating centre task force on mild traumatic brain injury. J Rehabil Med. 2004 Feb 43 Suppl: $61-75$.

12. Norman GR. Biostatistics: the bare essentials. 2nd ed. Streiner DL, editor. Hamilton: B.C. Decker; 2000.

13. Wennberg JE. Dealing with medical practice variations: a proposal for action. Health Aff (Millwood). 1984;3(2):6-32.

14. Diagnostic and statistical manual of mental disorders: DSM-IV-TR. 4th ed, text revision. American Psychiatric Association and American Psychiatric Association, editors. Washington, DC: American Psychiatric Association; 2000.

15. Practice parameter: the management of concussion in sports. Report of the quality standards subcommittee. Neurology. 1997 Mar;48(3):581-5.

16. Alexander MP. Mild traumatic brain injury: pathophysiology, natural history, and clinical management. Neurology. 1995 Jul;45(7):1253-60.

17. Nell V, Yates DW, Kruger J. An extended Glasgow coma scale (GCS-E) with enhanced sensitivity to mild brain injury. Arch Phys Med Rehabil. 2000 May;81(5):614-7.

18. Rees PM. Contemporary issues in mild traumatic brain injury. Arch Phys Med Rehabil. 2003;84(12): 1885-94.

19. Tate RL, McDonald S, Lulham JM. Incidence of hospital-treated traumatic brain injury in an Australian community. Aust NZJ Pub Health. 1998 Jun;22(4):419-23.

20. Hebb MO, Clarke DB, Tallon JM. Development of a provincial guideline for the acute assessment and management of adult and pediatric patients with head injuries. Can J Surg. 2007 Jun;50(3): $187-94$ 